\title{
Caracterización morfológica del páncreas en alpacas (Vicugna pacos) neonatas y en fetos del último tercio de gestación
}

\author{
Morphological characterization of the pancreas in newborns and foetuses of \\ alpacas (Vicugna pacos) in the last third of gestation
}

\author{
Franck Casanova V. ${ }^{1}$, Alexander Chávez R. ${ }^{1,3}$, Miluska Navarrete Z. ${ }^{1}$, Nieves \\ Sandoval C. ${ }^{2}$, Alberto Sato S. ${ }^{1}$, Francisco Santos R. ${ }^{1}$
}

\section{ReSUMien}

\begin{abstract}
El presente estudio tuvo como objetivo identificar y describir las características macroscópicas y microscópicas de la anatomía del páncreas de la alpaca, tanto en fetos del último tercio de gestación como en neonatos (0-30 días). Se estudiaron los páncreas de tres fetos del último tercio de gestación, y de crías de alpaca recién nacidas $(n=3)$, de 0 días $(\mathrm{n}=5), 7$ días $(\mathrm{n}=5), 15$ días $(\mathrm{n}=5)$ y 30 días $(\mathrm{n}=5)$. En el estudio macroscópico se observó el páncreas in situ, sus conductos y su relación con otros órganos, tomándose medidas biométricas (longitud corporal, altura a la cruz, perímetro torácico y perímetro abdominal) y el peso de los individuos. Macroscópicamente, el páncreas es similar al de las alpacas adultas. Microscópicamente, el páncreas presenta una citoarquitectura celular definida, formada por acinos tubulares de citoplasma acidófilo, elongado, de núcleos basales e islotes irregulares (en cuanto a tamaño y forma), además de grupos celulares no diferenciados. Esta citoarquitectura varía en la primera semana de edad, donde la conformación de los acinos e islotes es irregular, presentando una alta tasa de división celular y gran cantidad de células precursoras distribuidas por todo el campo. La actividad celular disminuye con la edad, encontrándose en los animales de 30 días de nacidas una citoarquitectura bastante similar al de las alpacas adultas.
\end{abstract}

Palabras clave: alpaca; feto; morfología; neonato; páncreas

\footnotetext{
${ }^{1}$ Laboratorio de Anatomía Animal y Fauna Silvestre, Facultad de Medicina Veterinaria, Universidad Nacional Mayor de San Marcos, Lima, Perú

${ }^{2}$ Laboratorio de Histología, Embriología y Patología Veterinaria, Facultad de Medicina Veterinaria, Universidad Nacional Mayor de San Marcos, Lima, Perú

${ }^{3}$ E-mail: alexander.chavez@unmsm.edu.pe
} 
The objective of this study was to identify and describe the macroscopic and microscopic characteristics of the anatomy of the pancreas of alpacas, both in the last third of the gestation and in the neonate (0-30 days). The study included three foetuses and 18 alpaca crias ( 0 days [3], 7 days [5], 15 days [5], and 30 days [5]). In the macroscopic analysis, the pancreas was observed in situ, including its ducts and its relationship with other organs, taking biometric measures (body length, height at withers, thoracic perimeter, and abdominal perimeter), as well as the weight of the individuals. Macroscopically, the pancreas is alike to that of adult alpacas. Microscopically, the pancreas presents a definite cellular cytoarchitecture, formed by tubular acinar of acidophilic cytoplasm, elongated of basal nuclei and irregular islets (in size and shape), as well as undifferentiated cell groups. This cytoarchitecture varies in the first week of age, where the conformation of acini and islets is irregular, presenting a high rate of cell division and a great number of precursor cells distributed throughout the field. The cellular activity diminishes with the age, being found in the animals of 30 days a cytoarchitecture quite alike to the one of the adult alpacas.

Key words: alpaca; fetus; morphology; newborn; pancreas

\section{INTRODUCCIÓN}

Los camélidos sudamericanos son especies nativas de la región altoandina del Perú y otros países de América del Sur. El Perú es el principal productor de alpacas (Vicugna pacos), albergando más del $85 \%$, representado por 3596753 alpacas, donde cerca del total de la población de alpacas se encuentra en la sierra de Perú (INEI, 2012). La fibra proveniente de la cría de alpaca es de gran finura $y$, por consiguiente, de mayor valor; sin embargo, el desarrollo económico se ve limitado por factores como el alto índice de mortalidad neonatal (Ramírez, 1987; Ramírez y Ellis, 1988), siendo los primeros 30 días los más críticos (Ameghino y De Martini, 1991), especialmente por causas asociadas a problemas digestivos.

Topográficamente, el páncreas de la alpaca se encuentra ubicado a nivel de la región del epigastrio dorsal, envuelto y fijado a los órganos que lo rodean por el mesoduodeno, omento mayor, ligamento gastroesplénico y mesocolon (Panesi, 2016). En los rumiantes, caballo y cerdo se encuentra desviado hacia el lado derecho de la región sublumbar (Sisson y Grossman, 2000). Es de color amarillo pardo rosáceo o amarillento en bovinos (Dyce et al., 1987), de color rojo o rojizo en equinos (Sisson y Grossman, 2000) y de color rosado gris en el camello (Alí y Masaad, 2007). En camélidos sudamericanos tiene una estructura lobulada de un color amarillo pálido (Navarrete y Sato, 2010), mientras que Panesi (2016) menciona que el páncreas de la alpaca tiene una coloración rosa pálido.

El páncreas, en todas las especies de producción, se compone de un lóbulo izquierdo, un lóbulo derecho y un cuerpo. En los camélidos sudamericanos se observa un gran desarrollo del lóbulo izquierdo y reducción del lóbulo derecho (Ghezzi et al., 2000). Algunas especies de animales tienen dos conductos pancreáticos; es decir, el conducto pancreático propiamente dicho que desemboca en el duodeno y el conducto accesorio que se puede encontrar en perros, caballos y en algunas ovejas (Konig et al., 2004) La alpaca no posee el conducto pancreático accesorio (Ghezzi et al., 2000). 
La irrigación del páncreas en los animales domésticos está a cargo de las arterias celiaca y mesentérica craneal. El lóbulo derecho recibe de la arteria pancreática duodenal craneal, y el lóbulo izquierdo y el cuerpo están irrigadas por la arteria esplénica y la pancreática duodenal (Konig et al., 2004). La inervación parasimpática proviene del tronco vagal y la simpática del plexo solar (Konig et al., 2004).

El páncreas es una glándula con función endocrina y exocrina, compuesta por cuatro componentes: el tejido exocrino, los conductos, las células endocrinas y el tejido conectivo. Estos elementos están relacionados íntimamente en ontogenia, anatomía, histología y función (Huaynates, 2015).

El sistema de conductos comienza con las células centro acinares, las cuales se encuentran en el lumen de los acinos (Longnecker, 2014), seguido de un conductillo intercalar estrecho, con epitelio bajo que desemboca en los conductos lobulillares. La reunión de los conductos lobulillares (intralobulillares) forma los interlobulillares y, la de estos, los conductos colectores principales (Difiori, 1986).

Las células endocrinas están reunidas en pequeños grupos, los islotes de Langerhans, que aparecen dispersos entre el tejido exocrino. Se encuentran rodeados por una fina malla de fibras reticulares y se encuentran muy vascularizados (Lis et al., 2003). Los islotes son fácilmente ubicados en ambos lóbulos y se encuentran al azar sin relación alguna con el sistema de conductos y su distribución es uniforme, lo cual es similar en otras especies (Xu et al., 1999; Cebra et al., 2006). Los islotes están en contacto cercano con los conductos en la etapa fetal y solo el $50 \%$ de ellos permanece cerca de los conductos en el adulto (Watanabe et al., 1999).

Huaynates (2015) determinó en fetos de alpaca la presencia de páncreas endocrino desde el primer tercio de gestación, siendo el mayor desarrollo en el último tercio de gestación. La identificación de células beta en cuyes (Cavia porcellus) desde el primer día de edad mediante la tinción específica de Tricrómico de Gomori, indica, en forma similar a la mayoría de mamíferos, que el proceso de diferenciación celular en el páncreas endocrino comienza en la etapa fetal (Rodríguez et al., 2012a).

El objetivo del presente estudio fue identificar y describir las características macroscópicas y microscópicas de la anatomía del páncreas de la alpaca en fetos del último tercio de gestación y en neonatos.

\section{MATERIALES y Métodos}

Se trabajó con hembras preñadas de raza Huacaya de descarte. Los animales pertenecían a comunidades alpaqueras de la sierra sur del Perú. Los animales o las crías resultantes fueron llevados a la estación experimental del Centro de Investigación IVITA, sede Maranganí, ubicada en el departamento de Cusco. Se trabajó con tres fetos del último tercio de gestación y con 18 crías distribuidas en cuatro grupos etarios ( 0 días [ $\mathrm{n}=3$ ], 7 días [5], 15 días [5], y 1 mes [5]).

Se registró la edad, sexo, peso, altura a la cruz, perímetro torácico, longitud corporal y perímetro abdominal de las crías (Cuadro 1). La edad gestacional en los fetos fue determinada utilizando como referencia las medidas biométricas fetales (diámetro biparietal), las cuales siguen un patrón de desarrollo constante durante la etapa fetal (Gazitua et al., 2001). Con base a esto, los fetos tenían 250, 278 y 306 días de gestación.

La eutanasia y disección de los animales se realizó en la sala de necropsia de la estación experimental, respetando las normas de bienestar animal, y con la autorización del Comité de Ética de la Facultad de Medicina Veterinaria (FMV) de la Universidad Nacional Mayor de San Marcos (UNMSM) (Có- 
digo 2017-005). Para el efecto, se administró acepromazina en dosis de $0.002 \mathrm{mg} / \mathrm{kg}$, vía endovenosa para la sedación, y pentobarbital sódico en sobre dosis $(60 \mathrm{mg} / \mathrm{kg})$ como eutanásico.

Luego del sacrificio, se procedió a la apertura de la cavidad abdominal mediante una incisión desde el xifoides hasta la región púbica y otra incisión bordeando los arcos costales con el fin de exponer las vísceras y determinar la ubicación in situ del páncreas. Se registraron sus características externas, relación con los órganos colindantes y vasos que lo irrigan. Luego de la extracción del páncreas, se apreció su forma y se determinó el peso, longitud y ancho de cada lóbulo y del cuerpo (Cuadro 1), así como la ubicación, longitud, diámetro y desembocadura del conducto hepatopancreático.

Se realizaron tres cortes por cada lóbulo pancreático (extremo, medio y base), dos cortes en el cuerpo y uno en el conducto hepatopancreático, que fueron conservados en formol tamponado al $10 \%$. Se llevaron al Laboratorio de Anatomía Animal y Fauna Silvestre de la Facultad de Medicina Veterinaria, Universidad Nacional Mayor de San Marcos, en Lima, Perú, donde se hizo el procesamiento de las muestras histológicas. Se hicieron cortes histológicos de $5 \mu \mathrm{m}$ de espesor y se tiñeron con hematoxilina de MayerEosina y tricrómico de Masson de acuerdo a los estándares descritos por Bancroft y Stevens (1996). La lectura de láminas se hizo con un microscopio binocular Leica.

\section{Resultados}

\section{Ubicación, Forma y Relaciones}

No se hallaron diferencias macroscópicas significativas en el páncreas en los grupos etarios. El órgano se encuentra situado a nivel del epigastrio dorsal, presenta un color rosado pálido, de bordes irregulares y de apariencia lobular. La forma del páncreas ase- meja a una «Y» invertida que va de craneal a caudal. Presenta un cuerpo, lóbulo derecho e izquierdo, siendo el lóbulo izquierdo más desarrollado (Figura 1).

La irrigación de este órgano está dada por la arteria pancreática duodenal craneal, la cual irriga al cuerpo y lóbulo derecho. La arteria pancreática duodenal caudal irriga al lóbulo izquierdo junto con ramas provenientes de la arteria esplénica. La inervación del páncreas está a cargo de las fibras autónomas que nacen del plexo iliaco. El lóbulo derecho y el cuerpo están inervados por el plexo hepático y el plexo mesentérico. El lóbulo izquierdo está inervado por el plexo esplénico.

\section{Conducto hepatopancreático}

El conducto pancreático emerge del lóbulo derecho y recibe al conducto biliar, denominándose conducto hepatopancreático, que va por el borde mesentérico del duodeno proximal y desemboca en el pliegue duodenal (Figura 2). Su origen se da en algunos individuos por el ingreso del conducto hepático al parénquima del lóbulo derecho.

\section{Medidas}

Como se observa en el Cuadro 2, el lóbulo izquierdo es más desarrollado que el lóbulo derecho, teniendo una longitud promedio mayor en cada grupo. El crecimiento más significativo se presentó en el cuerpo del páncreas, duplicando su peso al mes de edad. El peso del páncreas en relación al peso de animal fue desde 0.08 a $0.1 \%$ en fetos en el último tercio de gestación hasta $0.15-0.18 \%$ al mes de edad.

\section{Microscopía}

El páncreas está rodeado por una fina capa de tejido conectivo y revestido por un mesotelio de células planas. Esta capa se invagina formando tabiques con un conectivo más laxo, penetrando y formando los lóbulos y pseudolobulos (Figura 3-I). Además, se 


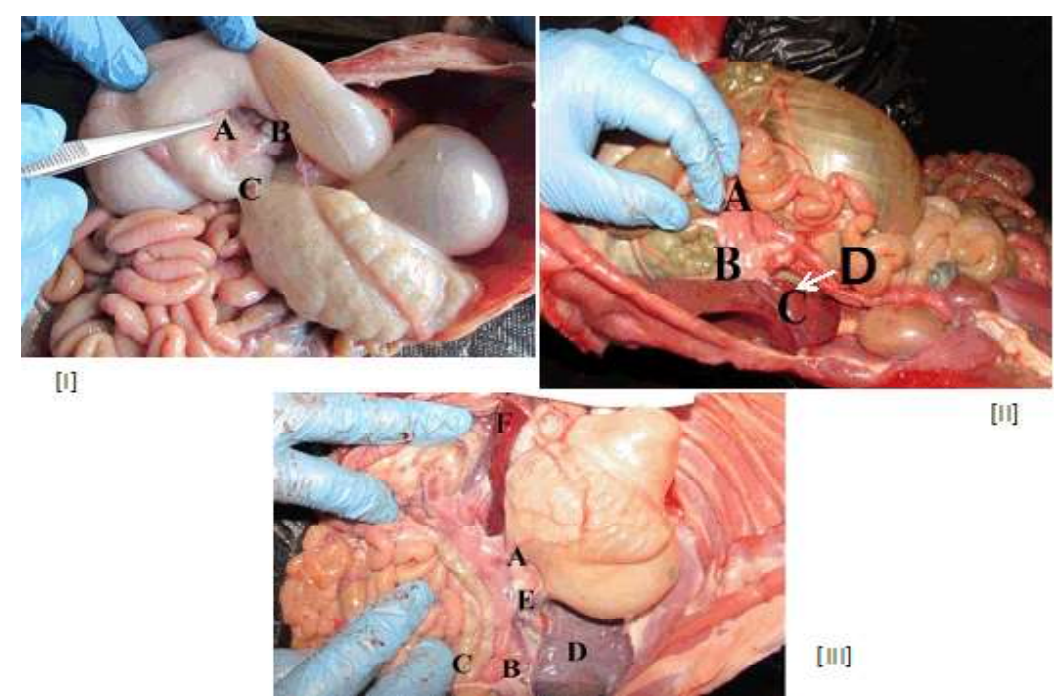

Figura 1. Observación macroscópica del páncreas de la alpaca a las dos semanas de edad. I. Cuerpo del páncreas caudal al píloro (A. cuerpo; B. lóbulo izquierdo, C. píloro). II. Ubicación del lóbulo derecho (A), y su relación con nódulos linfoides (B) y el lóbulo caudado del hígado (C), que se dirige caudalmente junto al duodeno descendente (D). III. Ubicación de la base del lóbulo izquierdo (A) relacionado con la cara visceral del compartimiento proximal del estómago y vértice del lóbulo izquierdo (B), colindando por el colon descendente (C) y el bazo (D). Además, se aprecian ramas vasculares esplénicas que recogen sangre del lóbulo izquierdo (E) e hígado relacionado al lóbulo derecho $(\mathrm{F})$

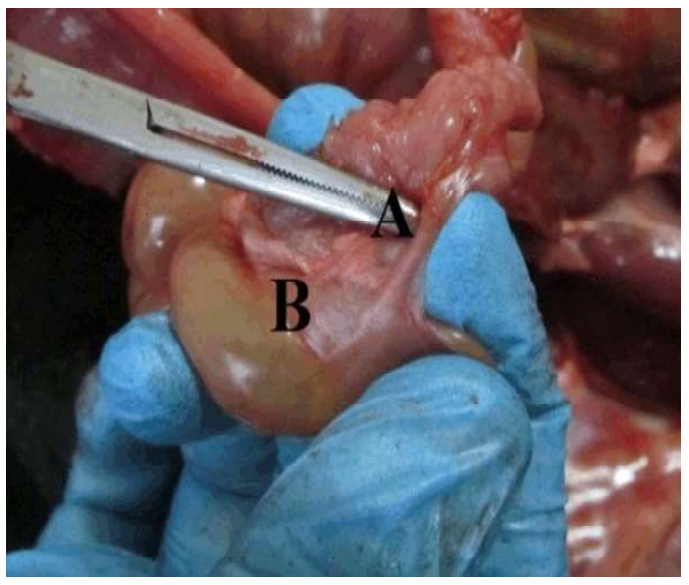

Figura 2. Alpaca de una semana de edad. Se observa el conducto hepatopancreático (A) que emerge del lóbulo derecho y desemboca en la ampolla duodenal (B)

observan pequeños vasos sanguíneos y nervios. Los tabiques contienen fibras colágenas, que rodean los vasos sanguíneos, paquetes nerviosos y los conductos (Figura 3-II). Esta disposición la presentan todos los animales del estudio independientemente de la edad.

\section{Porción Exocrina y Endocrina}

Las porciones exocrinas y endocrinas del páncreas presentaron diferencias estructurales según la edad. Las características según el grupo etario se describen a continuación:

\section{Fetos en el último tercio de gestación}

- Porción exocrina: Los acinos tiene forma tubular alargada y los núcleos de la célula secretora son basales, con citoplasma acidófilo. Entre el tejido conectivo que está formado por fibras colágenas se encuentran células indiferenciadas (Figura 4-I).

- Porción endocrina: Los islotes son irregulares, el número de células que conforman los islotes es variable, las células 
Cuadro 1. Datos biométricos del material biológico en estudio

\begin{tabular}{cccccc}
\hline Edad & $\begin{array}{c}\text { Peso } \\
(\mathrm{kg})\end{array}$ & $\begin{array}{c}\text { Altura } \\
(\mathrm{cm})\end{array}$ & $\begin{array}{c}\text { Largo } \\
(\mathrm{cm})\end{array}$ & $\begin{array}{c}\text { Perímetro } \\
\text { torácico }(\mathrm{cm})\end{array}$ & $\begin{array}{c}\text { Perímetro } \\
\text { abdominal } \\
(\mathrm{cm})\end{array}$ \\
\hline Feto & 7.5 & 54.5 & 37.0 & 37.0 & 26.3 \\
Neonato & 7.0 & 58.6 & 38.1 & 40.8 & 34.0 \\
7 días & 8.4 & 51.6 & 39.0 & 43.3 & 31.1 \\
15 días & 7.2 & 56.8 & 42.8 & 43.0 & 32.0 \\
30 días & 9.1 & 57.1 & 43.0 & 50.0 & 40.8 \\
\hline
\end{tabular}

Cuadro 2. Medida y peso promedio del páncreas ${ }^{1}$ de la alpaca en la etapa fetal y primer mes de edad

\begin{tabular}{ccccccccccccccc}
\hline \multicolumn{11}{c}{ Largo $(\mathrm{cm})$} & \multicolumn{10}{c}{ Ancho $(\mathrm{mm})$} \\
\hline Edad & Peso $(\mathrm{g})$ & LI & LD & C & CP & LIe & LIm & LTb & LDe & LDm & LDb & Ce & Cb & CP \\
\hline Feto & 6.63 & 7.0 & 4.6 & 1.8 & 0.9 & 5.4 & 7.2 & 5.1 & 6.3 & 4.6 & 7.1 & 5.6 & 4.8 & 2.2 \\
$0 \mathrm{~d}$ & 6.1 & 7.7 & 2.8 & 1.3 & 1.2 & 9.4 & 8.2 & 7.4 & 10.4 & 8.0 & 7.2 & 5.6 & 7.1 & 1.7 \\
$7 \mathrm{~d}$ & 8.0 & 8.3 & 3.6 & 2.6 & 1.1 & 9.8 & 6.9 & 7.2 & 7.1 & 7.3 & 7.5 & 7.8 & 7.9 & 1.9 \\
$15 \mathrm{~d}$ & 12.7 & 7.5 & 3.5 & 2.3 & 0.5 & 9.3 & 9.7 & 10.3 & 10.8 & 15.9 & 15.8 & 7.1 & 8.4 & 1.8 \\
$30 \mathrm{~d}$ & 13.2 & 9.9 & 4.4 & 4.0 & 1.5 & 12.0 & 9.5 & 8.8 & 9.6 & 11.4 & 11.0 & 7.8 & 8.5 & 2.6 \\
\hline
\end{tabular}

${ }^{1}$ LI: lóbulo izquierdo, LD: lóbulo derecho, C: cuerpo, CP: conducto, Lle: lóbulo izquierdo externo, LIb: lóbulo izquierdo base, LIm: lóbulo izquierdo medio, LDe: lóbulo derecho externo, LDb: lóbulo derecho base, LDm: lóbulo derecho medio, Ce: cuerpo externo, Cb: cuerpo base, CP: conducto pancreático

que los conforman son pequeñas y redondas, de núcleo basófilo y citoplasma tenuemente basófilo (Figura 4-II).

\section{Alpacas neonatas}

- Porción exocrina: Los acinos son largos y tubulares. Se observa separación entre acinos. Los núcleos de la célula secretora son basales y el citoplasma acidófilo (Figura 5-I). En la cápsula se encuentran células que aún no se diferencian que se distribuyen formando nidos celulares. Los núcleos de estas células se van juntando formando rosetas (Figura 5-II).
- Porción endocrina: Los islotes son irregulares e indefinidos, formados por células de núcleo basófilo y citoplasma tenuemente basófilo. Hay una mayor separación entre las células de los islotes (Figura 5-III). En el tejido conectivo se encuentran paquetes ordenados de células cúbicas que vienen desde un tabique y que migran hacia el centro y tienden hacerse redondas, con tendencia a diferenciarse (Figura 5-IV).

Alpacas de 7 dias

- Porción exocrina: Las células acinares presentan un núcleo central, dividiendo al citoplasma en una parte basófila basal 


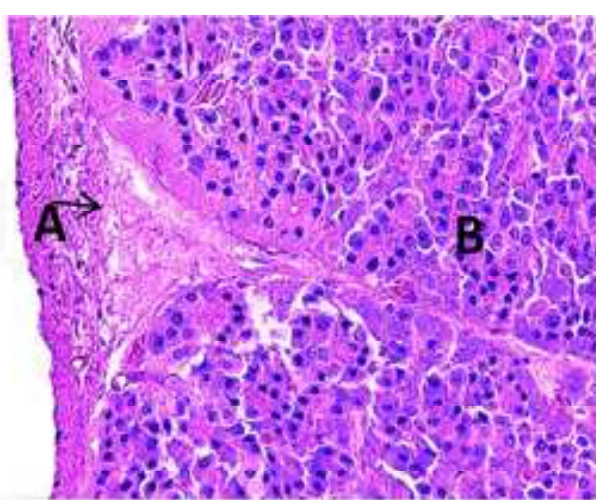

[1]

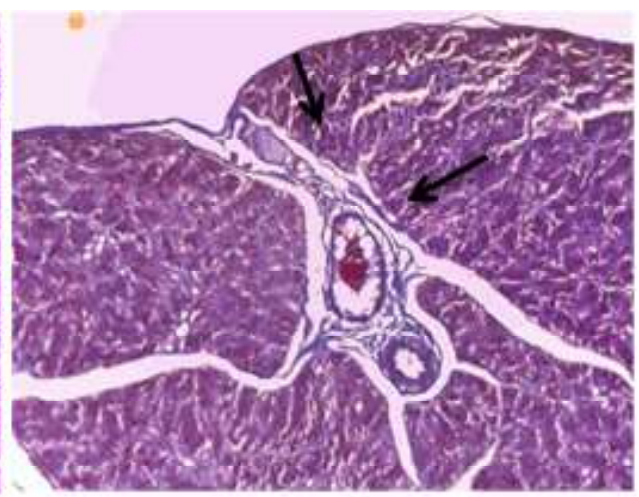

[II]

Figura 3. Cortes histológicos del páncreas de una alpaca de un mes de edad. I. Se observa la cápsula rodeada por mesotelio de células planas (A), que proyecta tabiques formados por tejido conectivo laxo formando septos en el parénquima pancreático (B) (H-E 400x). II. Tejido conectivo formando los pseudolóbulos y rodeando los vasos sanguíneos (flechas) (Tricrómico de Masson, 400x)

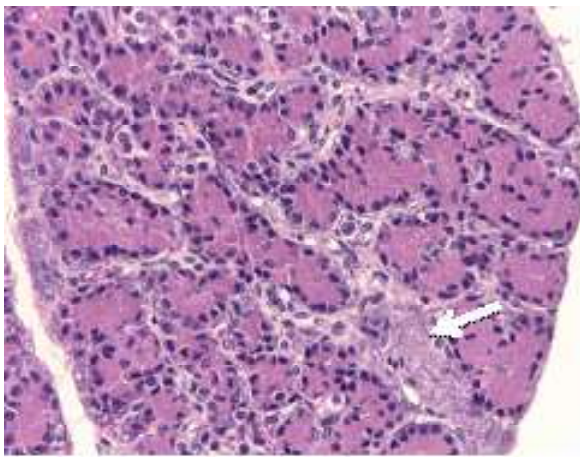

[1]

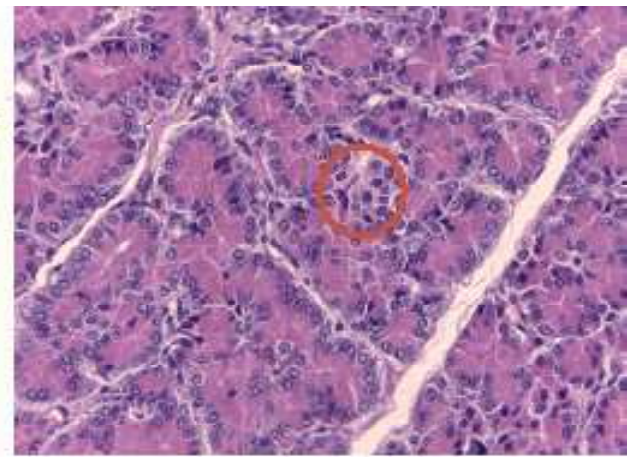

[II]

Figura 4. Cortes histológicos del páncreas de fetos de alpaca en el último tercio de la gestación. I. Se observan acinos, citoplasma alongado de forma tubular y la célula acinar de núcleo basal. La flecha indica fibras colágenas formando el tejido conectivo (H-E 400x). II. El círculo marca un islote conformado por escasa cantidad de células pequeñas de núcleo basófilo y citoplasma tenuemente basófilo (H-E 400x)

y otra acidófila (Figura 6-I). Hay una alta tasa de división celular ( 10 a 12 células por campo). Las figuras de mitosis están caracterizadas por núcleos en forma de estrella, en huso e intensamente basófilo. También se observan núcleos con la cromatina dispersa. (Figura 6-II).
La conformación acinar es irregular, habiendo áreas donde no se ve el detalle celular. Se observan células redondas a poliédricas, globosas de citoplasma basófilo con núcleo hacia la luz formando un posible acino (Figura 6-III). 
- Porción endocrina: Hay menor actividad celular a diferencia de las células acinares. Las células de los islotes son redondas de citoplasma claro. En el núcleo se observa la cromatina dispersa y en condensación de la cromatina en otros. En algunas áreas no hay detalle celular definido (Figura 6-IV).

\section{Alpacas de 15 días}

- Porción exocrina: Entre los acinos se ven espacios discretos formado por tejido conectivo laxo. Los acinos presentan en su mayoría un núcleo basal; pocos presentan núcleos ligeramente centrales separando el citoplasma celular en una porción basófila asociada a la base de la célula y otra acidofila, en la cual se encuentran pocas granulaciones (Figura 7-I).

- Porción endocrina: Los islotes tienen la cromatina muy granular, citoplasma acidófilo tenue (Figura 7-II), aunque en algunos casos son intensamente basófilos. En los núcleos más claros, la cromatina se dispersa. Hay islotes de diferentes tamaños de pequeños a grandes, siendo estos nodulares o irregulares.

\section{Alpacas de 30 días}

- Porción exocrina: Los acinos son de forma y tamaño variable. Pueden ser alargados a redondos, con un número variable de células. Los acinos redondos pequeños están formado por 4-15 células de morfología variable (desde poliédricas hasta prismáticas). Los núcleos son basales, ligeramente excéntricos, redondos. Pocos núcleos varían en tamaño. El citoplasma que se asocia al núcleo es más basófilo, y el que se encuentra hacia la luz es más acidófilo, con presencia de finas granulaciones acidófilas (Figura 8-I).

- Porción endocrina: El islote se ve como un grupo celular no definido de células más pequeñas y redondas, en comparación a las células secretoras de los acinos, de núcleo basófilo y de citoplasma claro (Figura 8-II). Por cada lóbulo se pueden contar de 2 a 4 islotes.

\section{Conductos}

- Células centroacinares: Las células se encontraron situadas en el lumen de los acinos, a partir de las cuales se forman los conductos intercalados. Estas células presentan un epitelio cúbico simple (Figura 9-I).

- Conductos intralobulillares: Presentan un epitelio cúbico simple y se encuentran distribuidos entre los acinos pancreáticos (Figura 9-II).

- Conducto interlobulillar: Se encuentra en los tabiques del tejido conectivo. Dependiendo a su tamaño se les puede encontrar con epitelio cúbico simple en conductos pequeños y en más grandes con un epitelio columnar (Figura 9-III).

- Conducto hepatopancreático: Presenta una mucosa formada por epitelio cilíndrico simple con microvellosidades. En la submucosa se puede apreciar abundante cantidad de glándulas formadas por células piramidales cúbicas con núcleos redondos basales, tejido conectivo de fibras principalmente colágenas. Todo ellos se encuentran rodeados por tejido muscular liso (Figura 9-IV).

\section{Discusión}

La ubicación in situ del páncreas de las alpacas en el último tercio, en neonatas y jóvenes es en el epigastrio dorsal, encontrándose la misma ubicación en alpacas adultas en los estudios realizados por Málaga (1976) y Panesi (2016), difiriendo con otras especies domésticas. En carnívoros, rumiantes, cerdos y equinos el páncreas se localiza en la línea media, con una mayor porción de la masa hacia el lado derecho (Málaga, 1976).

La coloración del páncreas de la alpaca es de rosa claro a rosa intenso. Estudios realizados por Navarrete y Sato (2010) mencionan una coloración amarillo pálido; asimismo, Panesi (2016) lo describe con un color rosa pálido. El color del páncreas de la alpaca difiere de otras especies domésticas, siendo 


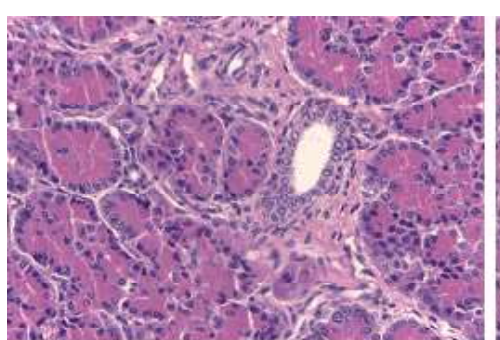

[1]

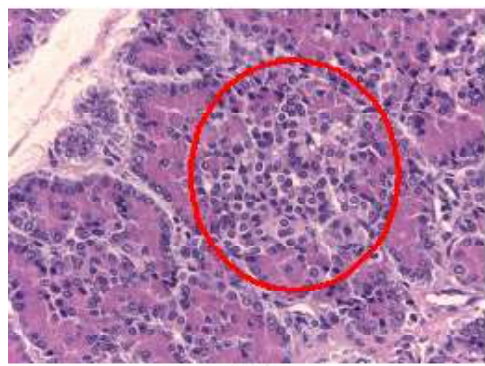

[III]

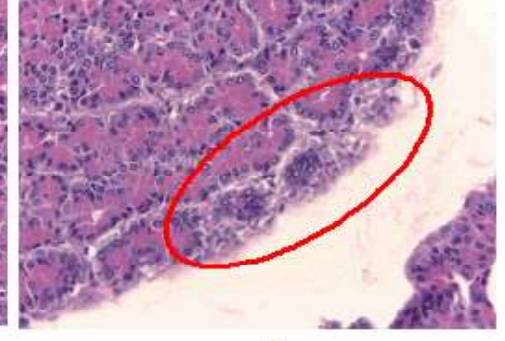

[II]

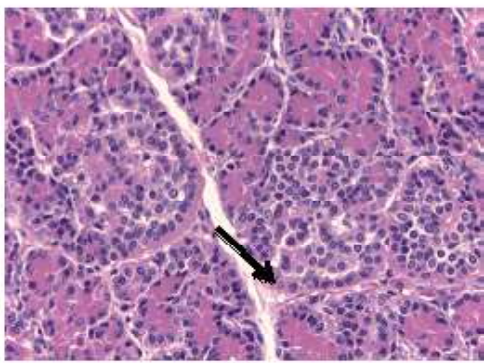

[IV]

Figura 5. Cortes histológicos del páncreas de alpacas recién nacidas. I. Se observa acinos glandulares alargados de forma tubular, con núcleos de la célula secretora basales y un conducto interlobulillar rodeado por tejido conectivo (H-E 400x). II. Se observa la presencia de células no diferenciadas en la cápsula (círculo) formando nidos celulares (H-E 400x). III. Se observa un islote no definido (círculo) formado por células de núcleo basófilo y citoplasma tenuemente basófilo (H-E 400x). IV. La flecha indica cordones celulares provenientes del tabique con tendencia a formar islotes (H-E 400x)

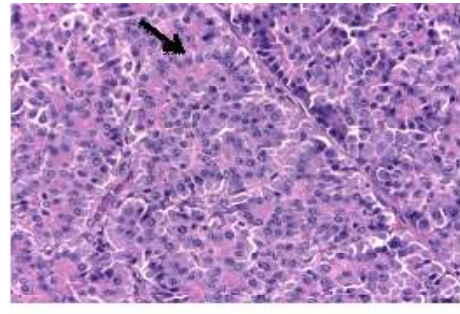

[1]

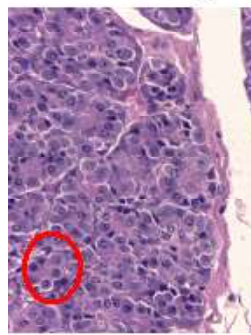

[III]

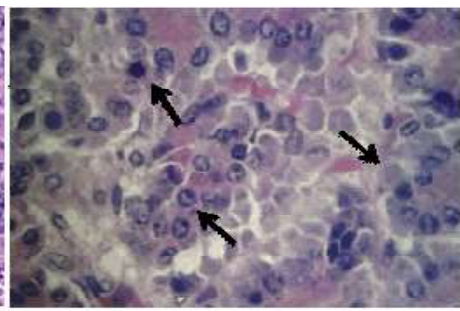

[II]

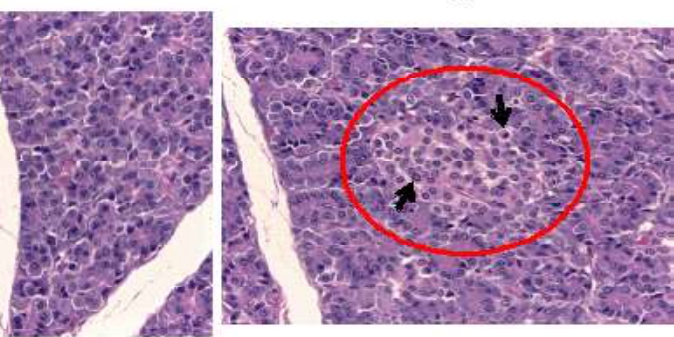

[IV]

Figura 6. Cortes histológicos del páncreas de alpacas de 7 días. I. La flecha indica acinos glandulares con núcleo central dividiendo el citoplasma en una porción basófila basal y otra acidófila (H-E 400x). II. Las flechas indican figuras de mitosis donde se observan núcleos en forma de estrella, en huso y heterocromáticos (H-E 400x). III. En el campo se observan células redondas a poliédricas, globosas de citoplasma basófilo formando futuros acinos (H-E 400x). IV. Islote en el círculo. Las flechas indican condensación de la cromatina y dispersión de la cromatina (H-E 400x) 

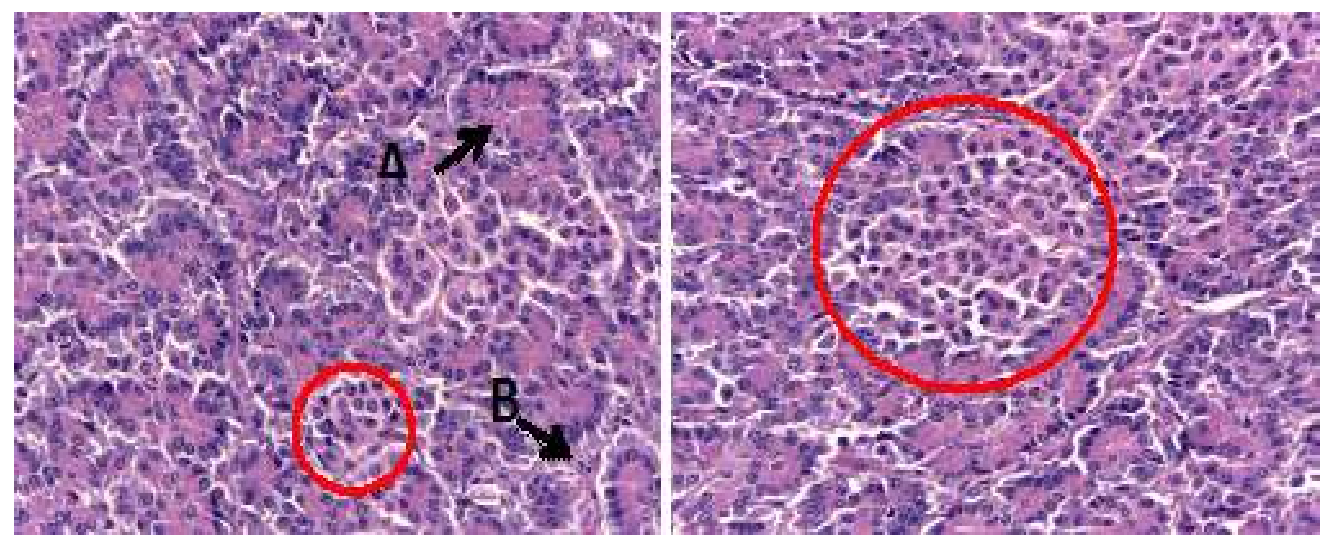

Figura 7. Cortes histológicos del páncreas de alpacas de 15 días. I. Las flechas indican acinos glandulares con núcleo basal (A) y con núcleos centrales (B). En el círculo rojo se ve un pequeño islote (H-E 400x). II. En el círculo rojo se observa un islote de Langerhans formado por células redondas de núcleo basófilo y citoplasma acidófilo (H-E 400x)
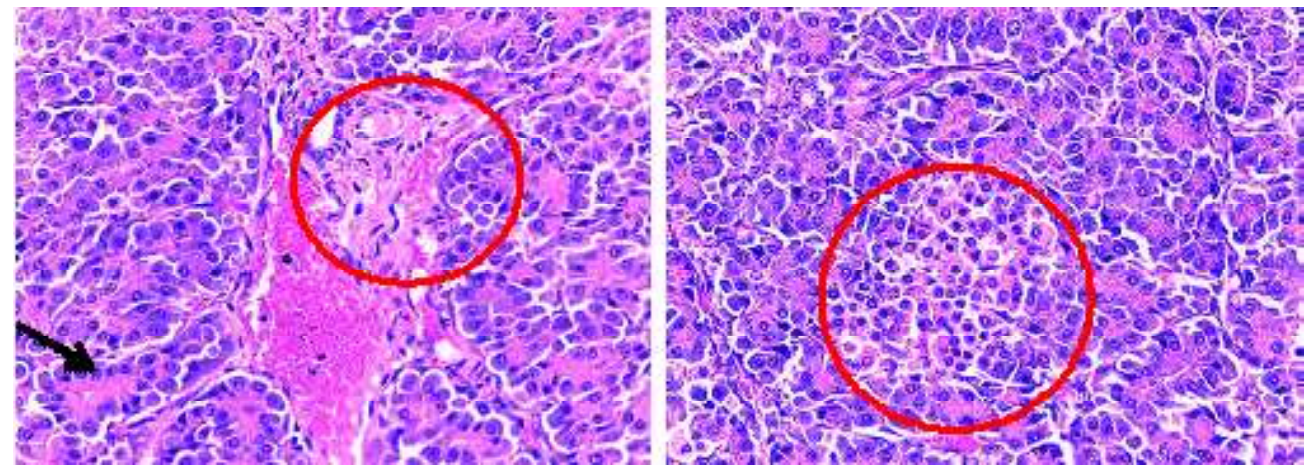

Figura 8: Cortes histológicos del páncreas de alpacas de 30 días. I. En el círculo rojo se observa la triada (arteria, conducto y nervio) rodeada de tejido conectivo. La flecha indica un acino glandular de núcleo basal y citoplasma acidófilo (H-E 400x). II. En el círculo rojo se observa un Islote de Langerhans formado por grupos células pequeñas y redondas de citoplasma acidófilo (H-E 400x)

rojizo a rosa en el equino, amarillo rojizo en cerdos, amarillo pardo en bovinos y rosa grisáceo en camellos (Dyce et al., 1987; Sisson y Grossman, 2000; Alí y Masaad, 2007).

En el páncreas de la alpaca se diferencia un cuerpo, un lóbulo derecho y un lóbulo izquierdo más desarrollado, los cuales le dan la forma de «Y» invertida; la misma forma descrita en alpacas adultas por Málaga (1976) y Panesi (2016) y en el camello por Alí y Masaad (2007). Su forma también difiere de las otras especies domésticas, donde los carnívoros presentan una forma de $\langle\mathrm{V}\rangle\rangle$, los rumiantes presentan un lóbulo derecho largo en comparación con el izquierdo, el equino presenta un lóbulo izquierdo largo y un lóbulo derecho corto, mientras que el cerdo presenta un cuerpo largo y dos pequeños lóbulos (Dyce et al., 1987; Sisson y Grossman, 2000; Konig et al., 2004). 


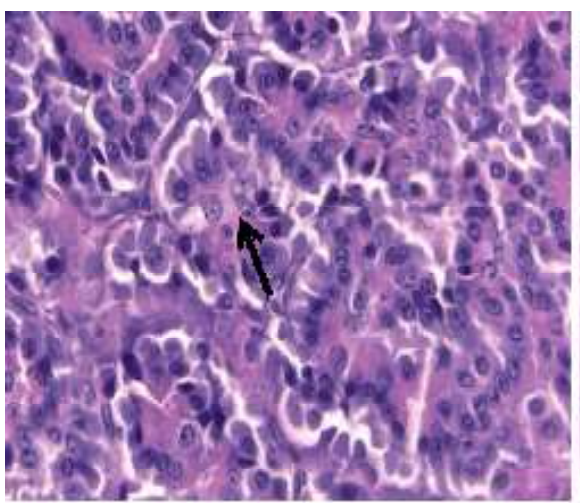

[1]

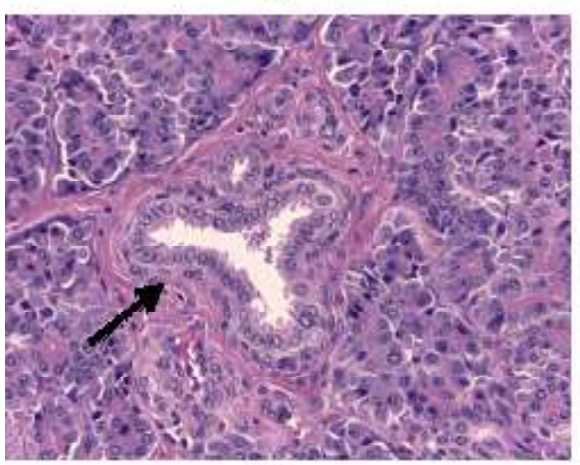

[III]

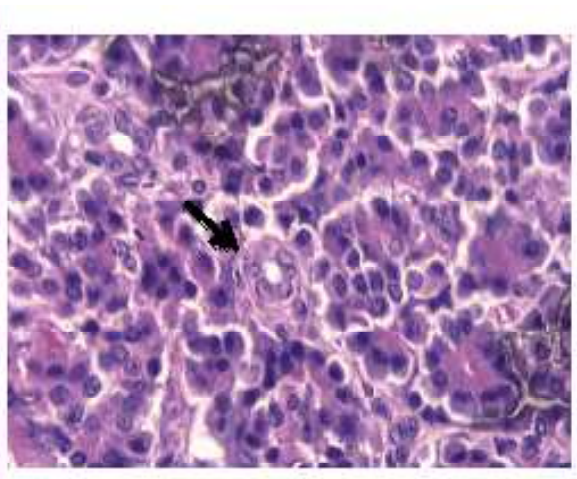

[II]

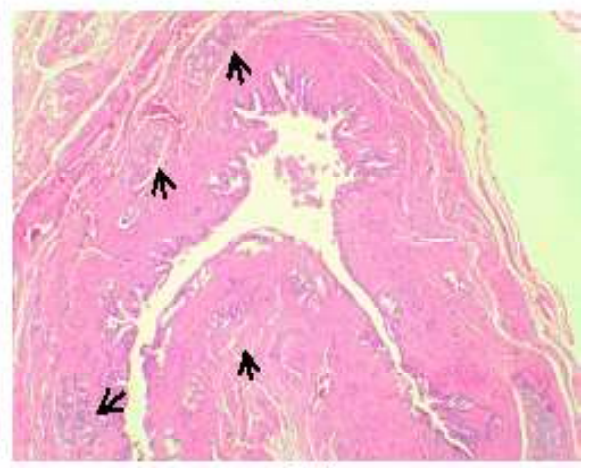

[IV]

Figura 9. Cortes histológicos de los conductos y conductillos del páncreas de alpacas. I. Alpaca de 15 días. La flecha indica células centroacinares formadas por células de epitelio cúbico simple (H-E 400x). II. Alpaca de 15 días. La flecha indica un conducto intralobulillar formado por epitelio cúbico simple (H-E 400x). III. Alpaca de 7 días. En el campo se observa un conducto intrerlobulillar formado por epitelio cúbico columnar (H-E 400x). IV. Alpaca de 30 días. Conducto hepatopancreático. Las flechas muestran una gran cantidad de glándulas alrededor del conducto (H-E 100x)

La alpaca posee un solo conducto pancreático, similar al vacuno, ovino, cerdo y gato (Málaga, 1976). En la alpaca el conducto pancreático se une al conducto hepático antes de desembocar en el duodeno para formar el conducto hepatopancreático. Ghezzi et al. (2000) mencionan, asimismo, que el conducto pancreático sale del lóbulo derecho del páncreas para unirse al conducto hepático, en tanto que Alì y Masaad (2007) describen que el conducto hepático en el camello se introduce en el parénquima del lóbulo derecho del páncreas para salir como conducto hepatopancreático.
Histológicamente el páncreas está rodeado por una fina capa o cápsula de tejido conectivo y revestido por un mesotelio. Esta capa se invagina formando los lóbulos y pseudolóbulos. Los tabiques también contienen tejido adiposo, vasos sanguíneos, fibras nerviosas y los conductos. Similar disposición se encontró en alpacas adultas (Malaga, 1976; Panesi, 2016).

Scaglia et al. (1997) mencionan que el páncreas endocrino en la rata sufre una remodelación durante la segunda semana de edad, lo cual concuerda con los datos pre- 
sentados por Rodríguez et al. (2015), quienes señalan que el número de células en los islotes de la alpaca no presentan un cambio significativo con la edad, tal vez debido a que el tejido del islote se 'diluye' por el crecimiento posnatal exuberante del tejido exocrino después del nacimiento. Sin embargo, nuevas células surgen por neogénesis o diferenciación de las células endocrinas del islote del epitelio ductal o por la replicación de las células de islotes existentes (Rodríguez et al., 2015).

Los conductos pancreáticos intercalares, intralobulillares e interlobulillares presentan la misma citoarquitectura mencionada por Málaga (1976) y Panesi (2016), estando formados por epitelio cúbico simple y, en algunos casos de conductos de mayor tamaño, por epitelio columnar. El conducto hepatopancreático es igual al descrito por Panesi (2016) en alpacas adultas, presentando una mucosa formada por epitelio cilíndrico simple con micro vellosidades, submucosa con abundantes glándulas y tejido conectivo y rodeado por tejido muscular liso.

\section{Conclusiones}

- El aspecto macroscópico del páncreas de la alpaca difiere de las demás especies domésticas en cuanto a color, forma y ubicación.

- El peso del páncreas con relación al peso de animal va aumentando según la edad del animal, llegando al mes de edad a una relación parecida a la descrita en adultas.

- La irrigación e inervación del páncreas es similar a otras especies domésticas.

- El conducto hepatopancreático de alpacas menores de un mes de edad es macro- y microscópicamente similar al descrito en alpacas adultas.

- Microscópicamente, el páncreas en el último tercio de gestación y al nacer presenta una citoarquitectura definida, la cual entra en remodelación a la semana de edad, estableciéndose una arquitectura celular parecida a las adultas al mes de edad.

\section{Agradecimiento}

Los autores expresan su agradecimiento al FONDECYT CONCYTEC por el financiamiento otorgado para la realización del estudio mediante Convenio 097-2014.

\section{Literatura Citada}

1. [INEI] Instituto Nacional de Estadística e Informática. 2012. Resultados definitivos. IV Censo Nacional Agropecuario. İnternet + . Disponible en: http://proyectos.inei.gob.pe/web/ D o c u m e n t o s P u b i c o s/ ResultadosFinalesIVCENAGRO.pdf

2. Ali G, Masaad, GAM. 2007. A comparative morphological study on the pancreas of the dromedary and the donkey. MSc Thesis. Sudan: Univ of Khartoum. 160 p.

3. Ameghino E, De Martini J. 1991. Mortalidad en crías de alpacas. Lima: IVITA-PCAIRM. $121 \mathrm{p}$.

4. Bancroft JD, Stevens A. 1996. Theory and practice of histological techniques. $4^{\text {th }}$ ed. Edinburgh: Churchill Livingstone. $766 \mathrm{p}$.

5. Bock T, Kyhnel A, Pakkenberg B, Buschard K. 2003. The postnatal growth of the b-cell mass in pigs. J Endocrinol 179: 245-252.

6. Cebra CK, Bildfell RJ, Fischer KA. 2006. Microanatomic features of pancreatic islets and immunolocalization of glucose transporters in tissues of llamas and alpacas. Am J Vet Res 67: 524528. doi: 10.2460/ajvr.67.3.524

7. Dyce KM, Sack WO, Wensing CJG. 1987. Textbook of veterinary anatomy. Philadelphia: Saunders. 820 p. 
8. Frandson RD. 1967. Anatomía y fisiología de los animales domésticos. México: Internacional Americana. $428 \mathrm{p}$.

9. Gazitúa FJ, Corradini P, Ferrando G, Raggi LA, Parraguez VH. 2001. Prediction of gestational age by ultrasonic fetometry in llamas (Lama glama) and alpacas (Lama pacos). Anim Reprod Sci 66: 81-92. doi: 10.1016/S03784320(01)00083-5

10. Ghezzi MD, Alzola RH, Lupidio MC, Massone A, Castro AN, Rodríguez JA. 2000. Conducto hepatopancreático de la llama (Lama glama). Rev Chil Anat 18: 27-34. doi: 10.4067/S071698682000000100004

11. Hazelwood RL. 1989. Embryology and anatomical organization of the vertebrate pancreas. In: The endocrine pancreas. NJ, USA: Prentice-Hall. p 9-15.

12. Huaynates J. 2015. Asociación entre el desarrollo del páncreas endocrino fetal y los niveles de glucosa séricos fetal y maternal en alpacas. Tesis de Médico Veterinario. Lima: Univ. Nacional Mayor de San Marcos. 55 p.

13. Konig HE, Liebich HG, Bragulla $H$. 2004. Veterinary anatomy of domestic mammals: textbook and colour atlas. New York: Schattauer. $681 \mathrm{p}$.

14. Lis A, Barra F, Beltramino F, Peralta $C$, Rejf P. 2003. Páncreas: diferencias microestructurales y de indicadores funcionales. [Internet]. Disponible en: http:/ /www.produccion-animal.com.ar/ informacion_tecnica/destete/58pancreas.pdf

15. Longnecker DS. 2014. Anatomy and histology of the pancreas. Pancreapedia: The exocrine pancreas knowledge base. [Internet]. Available in: https:// www.pancreapedia.org/sites/default/ files / V 2.\%20 Mounted\%20927\%20updated.pdf.pdf

16. Málaga J. 1976. Descripción anatomohistológica del páncreas de la alpaca. Tesis de Médico Veterinario. Puno: Univ Técnica del Altiplano. $43 \mathrm{p}$.
17. Navarrete M, Sato A. 2010. Aspectos anatómicos de la cría de alpaca. En: Sanidad de alpacas en la etapa neonatal. Manual para estudiantes y profesionales de veterinaria. España: Univ Complutense.p 51-62.

18. Panesi G 2016. Estudio morfológico del páncreas en alpacas (Vicugna pacos) jóvenes y adultas. Tesis de Médico Veterinario. Lima: Univ. Nacional Mayor de San Marcos. 42 p.

19. Ramírez A, Ellis R. 1988. Nuevos conceptos sobre la enterotoxemia y la colibacilosis en alpacas. Rev Camélidos Sudam 6: 9-1.

20. Ramírez A. 1987. Alpaca Clostridium perfringens type A enterotoxemia: purification and assays of the enterotoxin. PhD Thesis. USA: Colorado State University. $201 \mathrm{p}$

21. Rodríguez J, Cueva S, Lira B, Espinoza J, Vásquez M. 2012b. Identificación inmunohistoquímica de transportadores de glucosa intestinal y absorción de glucosa durante el desarrollo y maduración del intestino delgado de crías de alpacas. Rev Inv Vet Perú 23: 126137. doi: $10.15381 /$ rivep.v23i2.892

22. Rodríguez J, Cueva S, Vásquez M, Lira B, Olivera L, Espinoza J. $2012 a$. Desarrollo postnatal del páncreas endocrino de cuyes (Cavia porcellus) lactantes. Rev Inv Vet Perú 23: 13-19. doi: 10.15381/rivep.v23i1.877

23. Rodríguez J, Espinoza J, Rojas G, Lira $B$, Vásquez M, López B, Caro $C$. 2015. Desarrollo de los Islotes de Langerhans en páncreas de alpacas neonatas. Rev Inv Vet Perú 26: 381-388. doi: 10.15381/rivep.v26i3.11171

24. Scaglia L, Cahill C, Finegood D, Bonner-Weir S. 1997. Apoptosis participates in the remodeling of the endocrine pancreas in the neonatal rat. Endocrinology 138: 1736-1741. doi: 10.1210/endo.138.4.5069

25. Sisson S, Grossman JD. 2000. Anatomía de los animales domésticos. $5^{\circ}$ ed. Madrid: Salvat. 1335 p. 
26. Skau M, Pakkenberg B, Buschard K, Bock T. 2001. Linear correlation between the total islet mass and the volume-weighted mean islet volume. Diabetes 50: 1763-1770.

27. Sultan HS. 1999. Some morphological studies on the pancreas of the camel (Camelus dromedarius). MSc Thesis. Sudan: University of Khartoum. 160 p.
28. Watanabe T, Yaegashi H, Koizumi M, Toyota T, Takahashi T. 1999. Changing distribution of islets in the developing human pancreas: a computer assisted three-dimensional reconstruction study. Pancreas 18: 349-354.

29. Xu RJ, Wang T, Zhang SH. 1999. Functional structure and growth of the pancreas in postnatal growing animals. In: Biology of the pancreas in growing animals. Amsterdam: Elsevier. p 15-26. 